\title{
Una mirada a la aplicación de la física médica en el tratamiento del cáncer
}

\author{
María Cristina Plazas \\ Grupo de Física Médica, Departamento de Física, Universidad Nacional de Colombia; \\ Física Médica, Instituto de Oncología "Carlos Ardila Lulle", Fundación Santa Fe de Bogotá, Bogotá, D.C., Colombia
}

En la última mitad del siglo $X X$, el crecimiento acelerado de los avances científicos y tecnológicos en el diagnóstico y el tratamiento de diversas enfermedades convirtieron el conocimiento médico en el punto de encuentro de diversas áreas de la ciencia. En una u otra forma, médicos, físicos, ingenieros y personal paramédico aportaron su saber en la búsqueda del bienestar y de la salud del ser humano, mejorando así notablemente la calidad y la esperanza de vida de la sociedad del siglo XXI.

La Física ha estado presente en el nacimiento de estas nuevas tendencias y su influencia ha sido determinante en su construcción. Esta estructura se conoce genéricamente como Física Médica, y su campo de acción se refleja, prácticamente, en todas las áreas de la investigación médica. En especial en lo relacionado con el cáncer, afección en la que ciertas células del organismo se multiplican sin control aparente destruyendo tejidos y órganos sanos, es posible combatirlo con eficacia gracias al desarrollo de tratamientos, entre los que se encuentra la implementación de las terapias con radiación, las que hoy en día se han convertido en realidad como consecuencia del trabajo conjunto de profesionales altamente calificados (1).

Este desarrollo comenzó a gestarse hace más de cien años. La utilización de radiaciones en el tratamiento de enfermedades malignas, empleada

Correspondencia:

María Cristina Plazas

Grupo de Física Médica, Departamento de Física, Universidad Nacional de Colombia.

Teléfono 3165000 extensión 13082

mcplazasd@unal.edu.co

Recibido: 05/07/05; aceptado: 04/08/05 de manera aislada o en combinación con fármacos, ha sido posible gracias al descubrimiento de los rayos X por William Konrad Roentgen, físico alemán y primer premio Nobel de Física. En esa misma época, en 1896, Henri Becquerel, físico francés, descubrió una nueva propiedad de la materia que, posteriormente, denominó radiactividad y que lo llevó a compartir el premio Nobel de Física con Pierre y Marie Curie. Tal fenómeno se desprendió de su investigación sobre la fluorescencia cuando, al colocar sales de uranio sobre una placa fotográfica en una zona oscura, se observó que dicha placa se ennegrecía, dado que las sales de uranio emitían una radiación capaz de atravesar papeles negros y otras sustancias opacas a la luz ordinaria (2).

Marie Slodowska Curie se interesó en los recientes descubrimientos sobre los nuevos tipos de radiación, tanto aquéllos descritos por Roentgen como los de Becquerel. Comenzó a estudiar las radiaciones del uranio $y$, utilizando las técnicas piezoeléctricas inventadas por su esposo, Pierre Curie, midió cuidadosamente las radiaciones en un mineral que contenía uranio. Cuando vio que las radiaciones del mineral eran más intensas que las del propio uranio, se dio cuenta que debían existir elementos desconocidos, incluso, más radiactivos que el mismo uranio. Marie Curie fue la primera en utilizar el término "radiactivo" para describir los elementos que emiten radiaciones cuando se descomponen sus núcleos.

Posteriormente, Pierre Curie se unió a la investigación de su esposa y, en 1898, el matrimonio anunció el descubrimiento de dos nuevos elementos: el polonio (Marie le dio ese nombre en honor de su Polonia natal) y el radio (3). Durante los cuatro años siguientes, los Curie 
-trabajando en condiciones muy precarias- trataron una tonelada de ese mismo mineral, y aislaron una fracción de apenas un gramo de radio.

La aplicación en procesos oncológicos de esta nueva sustancia radiactiva, llamada radio, fue casi inmediata, gracias a que Pierre Curie puso a disposición del médico Henri Danlos, una determinada cantidad de este material radiactivo para fabricar aplicadores superficiales que sirvieran para el tratamiento de lesiones cutáneas. Desde este momento, los radioterapeutas han utilizado las radiaciones ionizantes como herramienta principal de sus tratamientos y muchos de los descubrimientos realizados por los físicos en el siglo XIX, hicieron posible los importantes avances con los que hoy contamos para el diagnóstico y el tratamiento de diversas enfermedades.

De esta manera, aparecen la radiología y la medicina nuclear como especialidades médicas que utilizan la radiación para el diagnóstico y el tratamiento de las enfermedades. El avance logrado ha sido muy importante en dos vertientes: la que concierne a la radiología diagnóstica y la que desarrolla la medicina nuclear al suministrar al paciente, por vía oral o intravenosa, un material radiactivo asociado con un fármaco, lo que permite realizar diagnósticos por imágenes, tales como las gammagrafías hepáticas u óseas, entre otros.

El cáncer, como principal objetivo de aplicación de esta nueva tecnología, es combatido con distintas medidas terapéuticas que incluyen la cirugía, la radioterapia y la quimioterapia. La radioterapia es la exposición de una zona determinada del organismo a una fuente de radiación ionizante; dicha radiación puede provenir de una fuente natural como los isótopos radiactivos, o de una fuente artificial como los rayos $\mathrm{X} u$ otros radioisótopos activados artificialmente.

El tratamiento incluye la localización precisa del tumor y la utilización de dosis fraccionadas múltiples, diarias o periódicas, de irradiación durante un periodo de tiempo determinado. La radiación ionizante lesiona las células mediante su interacción con el ácido desoxirribonucleico del núcleo (ADN), e impide la división celular normal.
El haz de radiación ionizante atraviesa los tejidos del paciente para eliminar las células cancerígenas que proliferan desordenadamente en el cuerpo (4). Ello es posible dada la naturaleza de estas radiaciones de mínima longitud de onda y de alta frecuencia, capaces de penetrar el órgano afectado con dosis previamente cuantificadas.

La radiación ionizante se diferencia de otras, como la luz visible o las ondas de radio, en que al entrar en contacto con la materia producen iones, es decir, átomos o grupos de átomos que han adquirido carga eléctrica. La radiación puede llegar directamente al núcleo de la célula, o de forma indirecta a través de las moléculas de agua del propio cuerpo, en un fenómeno físico conocido como radiólisis; en los dos casos, el fin es terapéutico. Al igual que los agentes citotóxicos utilizados en quimioterapia, la selectividad es limitada por lo que los efectos de este tipo de tratamiento para el cáncer lesionan, también, las células no cancerosas. Por este motivo, la radioterapia debe tener en cuenta la localización exacta del tumor que se va a irradiar para minimizar la exposición de los tejidos normales. Por consiguiente, en el tratamiento y diagnóstico de las enfermedades que utilizan radiaciones ionizantes, se hace necesario contar con un grupos multidisciplinario de trabajo de radioncólogos, médicos nucleares, radiólogos, físicos médicos y tecnólogos.

Los radioncólogos prescriben las dosis que consideran apropiadas, teniendo en cuenta criterios como la radiosensibilidad, pues existen tumores altamente sensibles ubicados en los órganos germinales: ovarios y testículos, el sistema hematopoyético, los pulmones, otros de rango medio (epitelios) y algunos con baja radiosensibilidad (sarcomas).

Los médicos nucleares hacen el diagnóstico con el uso de radiofármacos que contienen el isótopo radiactivo, mientras que los médicos radiólogos, diagnostican gracias al empleo de los rayos $X o$ de las radiaciones no ionizantes como herramientas (por ejemplo, ecografías y resonancias magnéticas, entre otras).

Los físicos médicos tienen gran responsabilidad sobre el correcto uso y manejo de las radiaciones 
ionizantes provenientes de los equipos emisores y las fuentes radiactivas; así mismo, deben garantizar las condiciones óptimas de seguridad para el personal ocupacionalmente expuesto, el paciente y el público en general; también, en la radioterapia la cual tiene diferentes modalidades de tratamiento, tales como la radioterapia convencional (teleterapia y braquiterapia) (5), la radioterapia conformal e intensa modulada y la radiocirugía. Por ello, los físicos médicos son los farmaceutas de las radiaciones ionizantes ya que garantizan que las dosis que prescriben los radioncólogos correspondan exactamente a las que el paciente recibe. Para lograr esto, adelantan programas de control de calidad que incluyen la calibración de los haces de radiación y de las fuentes radiactivas, así como de los parámetros físicos y mecánicos de los equipos. Su línea de investigación es conocida como dosimetría clínica.

Como es indispensable analizar cada paciente de manera individual para garantizar el éxito de su tratamiento con radiaciones ionizantes, se ingresan sus imágenes diagnósticas (tomografía computarizada o resonancia magnética, entre otras) al sistema de planeación dosimétrico, mediante el cual se construyen las distribuciones de las dosis sobre la zona que se va a tratar, de acuerdo con los campos de radiación prescritos por el radioncólogo.

El tratamiento actual con radiaciones ionizantes ha sufrido cambios importantes en la tecnología de los equipos de teleterapia y braquiterapia que se han utilizado tradicionalmente. La emisión de rayos $X$ o de electrones generada por los aceleradores lineales de diferentes modalidades tiene como objetivo depositar las dosis en forma similar. Sin embargo, hay que tener en cuenta las diferencias técnicas que se presentan en el diseño de estos aceleradores y de sus diferentes componentes para garantizar su óptimo desempeño: una larga vida útil del equipo, un tiempo mínimo de fuera de servicio y una excelente proyección futura para implementar nuevas modalidades de tratamiento.

Actualmente, ya se dispone en Colombia de equipos como los aceleradores duales (con dos energías de fotones y varias de electrones) y colimadores multihojas, los cuales permiten conformar de una manera precisa la magnitud del tratamiento, que aporta una dosis mayor al tumor y mínima al tejido sano adyacente. La modulación de la intensidad del haz de radiación mediante el uso de colimadores multihojas dinámicos (que se desplazan automáticamente dentro del haz), permite concentrar una dosis mayor sobre los focos tumorales dentro del mismo volumen blanco y minimizar la dosis a los tejidos sanos ubicados dentro del campo de radiación. Lo anterior no se logra mediante la terapia convencional.

En Colombia, el Instituto Nacional de Cancerología es un centro de alto nivel tecnológico y el único en el país que cuenta con programas de formación en Física Médica en conjunto con la Universidad Nacional de Colombia, los cuales funcionan desde 1986 (6). Gracias a ellos, se han adelantado conjuntamente diversas actividades sociales, científicas y académicas que concientizan a los profesionales sobre la importancia de observar de manera rigurosa los principios dosimétricos dentro de la física médica.

La cooperación institucional se ha concretado en convenios con los siguientes propósitos fundamentales: formar profesionales universitarios con posgrado en Física Médica que sean capaces de trabajar interdisciplinariamente con los médicos e ingenieros en el diagnóstico y el tratamiento de las enfermedades con los aceleradores lineales de electrones, capaces de producir energías muy altas, como las fuentes radiactivas de cobalto 60; igualmente, desarrollar trabajos de grado, de especialización y tesis de maestría; fortalecer líneas de investigación; en la actualidad cuenta con cuatro: dosimetría clínica, protección radiológica, instrumentación y radiobiología); desarrollar actividades de extensión (cursos, talleres, seminarios, congresos, etc.); brindar asesorías y servir como organismo consultor a instituciones y centros nacionales e internacionales que así lo requieran.

La formación de especialistas en el manejo de los usos de las radiaciones ionizantes es un requerimiento de primer orden, pues como se mencionó anteriormente, también se utilizan en 
tareas de diagnóstico; tanto en éstas como en los tratamientos terapéuticos es necesario saber cuánta radiación está recibiendo el paciente.

La labor interinstitucional prepara el terreno para la implementación en el país de las tecnologías más recientes en el mundo médico, tanto así que próximamente podremos contar en la Fundación Santa Fe de Bogotá con la más avanzada tecnología para realizar exámenes de diagnóstico; la tomografía por emisión de positrones (PET) con la producción de ${ }^{18} \mathrm{~F}-\mathrm{FDG}$ (fluorodesoxiglucosa), que se está convirtiendo en pieza fundamental de la investigación del metabolismo cerebral y clave diagnóstica de muchas enfermedades a nivel mundial, pues obtiene datos de forma no invasiva sobre flujos sanguíneos, metabolismo de la glucosa, transporte de aminoácidos, metabolismo de proteínas, estado de los neurorreceptores, consumo de oxígeno, división celular, etc. La naturaleza de los datos obtenidos con PET permite la investigación de los hechos que ocurren a nivel celular, entender mejor la evolución de la enfermedad y mejorar la terapia que se va a aplicar puesto que los cambios bioquímicos siempre preceden a las alteraciones anatómicas. Las indicaciones clínicas en oncología incluyen, entre otros: el diagnóstico diferencial (nódulo solitario de pulmón, carcinoma de páncreas) y la clasificación de tumores en sus estadios más iniciales (7).

De esta manera, hoy en día contamos en nuestro país con 42 centros de radioterapia, más de 200 centros de radiología y cerca de 25 centros de medicina nuclear. Las estadísticas demuestran cómo la demanda de estos nuevos tratamientos es cada vez mayor, gracias a los esfuerzos realizados por los profesionales anteriormente mencionados, entre ellos, los físicos médicos, cuya participación activa en la investigación y en el desarrollo de nuevas tecnologías es un componente primordial, como se demostró desde la época de los esposos Curie, quienes se sacrificaron al servicio de la ciencia, aun a costa de sufrir en sí mismos las consecuencias de la excesiva exposición a las radiaciones.

\section{Referencias}

1. Enciclopedia Microsoft $\circledast$ Encarta $\AA$ 2003. ( $)$ Microsoft Corporation1993-2002.

2. Antonie Henry Becquerel.15 de diciembre de 1852-25 de agosto de 1908. Wikipedia: enciclopedia libre.USA,s.f. Fecha de consulta: 1 de julio de 2005.Disponible en http://eswikipedia.org/wiki/ Henri_Becquerel.

3. Curie E, Curie P. La vida victoriosa de Marie curie. Fecha de consulta: 2 de julio de 2005. Disponible en www.geocities.com/Vienna/8762/Ciencia/Curie.htm

4. Castellanos Y. Dosis precisas contra el cáncer. Unimedios Universidad Nacional de Colombia. 10 de abril de 2005; UNP no. 73: Sección Ciencia.

5. Wikipedia. Braquiterapia. Fecha de consulta: 1 de julio de 2005. disponible en: http://es.wikipedia.org/wiki/ Braquiterapia

6. Instituto Nacional de Cancerología. Organigrama 2005. Fecha de consulta: 1 de julio de 2005. disponible en: http://www.incancerologia.gov.co/documentos/ 3_3_2005_9_55_08_AM_organig.swf

7. Radiological Society of North America. Positron Emission Tomography (PET Imaging). Radiologyinfo, 2005. Fecha de consulta: 19 de junio de 2005. Disponible en:http://www.radiologyinfo.org/content/ petomography.htm 